\title{
Broomrape Can Acquire Viruses from Its Hosts
}

\author{
Amit Gal-On, Anna Naglis, Diana Leibman, Hammam Ziadna, Kathir Kathiravan, Lambros Papayiannis, \\ Vered Holdengreber, Dana Guenoune-Gelbert, Moshe Lapidot, and Radi Aly
}

First, second, third, fourth, fifth, seventh, and tenth authors: Department of Plant Pathology and Weed Science, Volcani Center, ARO, Bet Dagan 50250; Sixth author Agricultural Research Institute, P.O. Box 22016, 1516 Nicosia, Cyprus; and eighth and ninth authors: Department of Vegetable Research, Volcani Center, ARO, Bet Dagan 50250.

Current address of K. Kathiravan: Department of Biotechnology, University of Madras, Chennai, India.

Accepted for publication 9 July 2009.

\begin{abstract}
Gal-On, A., Naglis, A., Leibman, D., Ziadna, H., Kathiravan, K., Papayiannis, L., Holdengraber, V., Guenoune-Gelbert, D., Lapidot, M., and Aly, R. 2009. Broomrape can acquire viruses from its hosts. Phytopathology 99:1321-1329.

Broomrapes (Phelipanche, formerly Orobanche) are parasitic plants that physically connect with the vascular systems of their hosts through haustorial structures. In this study, we found that Cucumber mosaic virus (CMV), Tomato mosaic virus (ToMV), Potato virus Y (PVY), and Tomato yellow leaf curl virus (TYLCV) translocate from infected host plants to Phelipanche aegyptiaca. In order to examine whether these viruses, and

panche grown on CMV-infected tobacco and tomato plants. We purified CMV particles from Phelipanche grown on CMV-infected plants. These particles were present in amounts comparable to those found in the hosts' leaves. These data indicate that CMV replicates in Phelipanche tissues. In addition, viable ToMV and PVY were observed, and the plus and minus strand RNAs of ToMV were detected in Phelipanche shoots grown on infected hosts. However, we found only low levels of ToMV coat protein and did not detect any PVY coat protein. We also detected genomic TYLCV DNA in shoots of Phelipanche grown on TYLCV-infected tomato. Thus, for the first time, we demonstrate that broomrape is a host for at least one plant virus CMV, and possibly various other viruses.
\end{abstract} specifically CMV, replicate in the parasite, we tested several replication parameters. We detected accumulation of both plus and minus strands of CMV genomic RNA and CMV-derived siRNAs in the shoots of Pheli-
Additional keywords: parasitic weed.
Parasitic plants display a wide range of parasitic strategies, from obligate holoparasitism to facultative hemiparasitism $(2,24)$. These plants and their hosts are physically linked by haustorial structures (26), which connect the parasite with the host's vascular system. Several parasitic weeds form connections with their hosts that contain both xylem and phloem bridges (15). The translocation and uptake of molecules and macromolecules from host plants by the parasites, especially Cuscuta sp., has been well documented. The movement of nucleic acids from host to parasite (12) or from parasite to host (35) is facilitated by direct contact between the host and the parasite. Physiological studies have documented the movement of radiolabeled sugar (1), herbicides $(25,36,46)$, and proteins between hosts and various parasitic plant species $(4,18,19)$. Additionally, specific tomato mRNA transcripts have been shown to move through the phloem of a host plant into Cuscuta sp. (44), and a silencing signal generated in transgenic host (siRNA) has been shown to silence exogenous transgene GUS in the Orobanchaceae parasite Triphysaria (48). Recently, we demonstrated the silencing of the parasitic M6PR endogenous gene as a result of the movement of a silencing signal from transgenic tomato roots into Phelipanche aegyptiaca Pers. (3).

Until recently, very little was known about the translocation of viruses and macromolecules such as nucleic acids or proteins from host plants to Phelipanche sp. (genus formerly named Orobanche). An early study (5-7) showed that viruses could be transmitted from an infected plant to a healthy plant through a dodder (Cuscuta spp.) plant that parasitized both the infected and the

Corresponding author: A. Gal-On; E-mail address: amitg@ volcani.agri.gov.il

doi:10.1094/PHYTO-99-11-1321

(C) 2009 The American Phytopathological Society healthy host plants, forming a bridge between them. Hosford (23) demonstrated the transmission of viruses from various taxonomic groups to different hosts by Cuscuta sp. However, dodder is a shoot parasite whose anatomy and haustorial connections are different from those of root-parasitic plants and the acquisition and transmission of viruses among different host plants has not been reported for root parasites such as Phelipanche.

Plant viruses move from cell to cell via cellular connections (plasmodesmata) in an active process that is mediated by specialized virus-encoded movement proteins $(8,21,32)$. Some viruses (i.e., Tobacco mosaic virus [TMV]) can move as ribonucleoprotein complexes (20). Other viruses (e.g., potyviruses, cucumovirus, and geminiviruses) probably move as assembled virions, in which the coat protein is essential for the virus's long-distance movement.

In this study, we used three positive single-stranded (ss) RNA viruses and one ssDNA virus, representing four distinct genera: Cucumovirus, Tobamovirus, Potyvirus, and Geminivirus.

Cucumber mosaic virus (CMV) has a broad host range, which includes more than 800 plant species, and is transmitted by aphids in a nonpersistent manner. CMV virions are isometric particles 30 $\mathrm{nm}$ in diameter, and the CMV genome is organized into three single-stranded genomic RNAs (RNAs 1, 2, and 3) and two major subgenomic RNAs (RNAs 4 and 4A). RNAs 1 and 2 code for components of the replicase complex. RNA 2 also codes for the $2 \mathrm{~b}$ protein $(4 \mathrm{~A})$, which is involved in the suppression of gene silencing. RNA 3 encodes the 3 a protein, which is essential for virus movement, and the coat protein $(24 \mathrm{kDa})$, which is expressed from subgenomic RNA 4 (39).

Tomato mosaic virus (ToMV) is mechanically transmitted and infects tobacco, tomato, and other Solanaceae. The rod-shaped virus (300 $\mathrm{nm}$ in length) consists of a single-stranded, messengersense RNA of about 6,400 nucleotides, which is encapsidated by a 
single coat protein $(\mathrm{CP})$. The RNA is capped at the $5^{\prime}$ end and a tRNA-like structure exists at the $3^{\prime}$ end. The RNA encodes two replicase proteins, $126 \mathrm{~K}$ and its read-through $183 \mathrm{~K}$. In addition to replication, $126 \mathrm{~K}$ is involved in cell-to-cell movement (30) and silencing suppression (14). In the $3^{\prime}$ region, a movement protein and a $17.5-\mathrm{kDa}$ coat protein are encoded. The replicase is translated from the genomic RNA that enters a cell, whereas the movement protein (MP) and CP are expressed from subgenomic RNAs that are produced during virus replication (20).

Potato virus $Y$ (PVY) is a flexuous filamentous virus that mostly infects Solanaceae species and is transmitted by aphids in a nonpersistent manner. The 9.6-kb RNA genome is covalently linked to a viral-encoded protein (the VPg) at the $5^{\prime}$ end and has a 3' poly-A tail. Translation of this RNA results in a polyprotein that is processed into 9 to 10 mature proteins (see review by Riechmann et al. [42]).

Tomato yellow leaf curl virus (TYLCV), a monopartite begomovirus, has a $20 \times 28 \mathrm{~nm}$ twinned isometric particle containing a circular single-stranded DNA molecule of 2,787 nucleotides. This virus, which infects tomato (Solanum lycopersicum Mill.) and a few other plant species, is transmitted by whitefly (Bemisia tabaci) in a persistent and circular manner. The virus's ssDNA genome is replicated in phloem cell nuclei via a rolling circle mechanism. The TYLCV genome encodes two genes on the viral strand (the coat and movement proteins) and four genes on the complementary strand (see review by Czosnek [10]).

In this study, we demonstrate, for the first time, the movement of three RNA viruses (CMV, ToMV, and PVY) and an ssDNA geminivirus (TYLCV) into the root-parasitizing plant $P$. aegyptiaca from its hosts. We also present data supporting the replication of CMV in P. aegyptiaca. We conclude that parasitic weeds, such as Phelipanche species, are virus hosts, like many other plant species.

\section{MATERIALS AND METHODS}

Parasite, host plants, and material. $P$. aegyptiaca seeds were collected from an infested tomato field in the Golan Heights, Israel (16) and used to infect tomato and tobacco host plants. Tomato (Solanum lycopersicum (Mill.) cv. Marmande) and tobacco (Nicotiana tabacum L. cvs. Samsun NN, Xanthi, and Samsun) plants that served as host plants were maintained in a temperature-controlled greenhouse at $25^{\circ} \mathrm{C}$ with supplementary lighting. Tobacco ( $N$. tabacum L. cvs. Xanthi, Samsun, and Samsun NN) and tomato (S. lycopersicum cv. Marmande) seedlings were used to maintain cultures of PVY, CMV, ToMV, and TYLCV, respectively, which were used as inocula.

Virus strains. Four viruses were tested: PVY strain-H $\left(\mathrm{PVY}^{\mathrm{H}}\right.$ accession no. M95491), which is closely related to a Hungarian strain (47); CMV (Fny-CMV) (43); ToMV (an Israeli strain closely related to ToMV1-2, accession no. DQ873692); and TYLCV (accession no. X15656) (37).

Field screening for virus-infected Phelipanche. During 2007 and 2008, a survey was conducted in a tomato field located in Lefkosia (Nicosia district), Cyprus, in order to identify TYLCV in Phelipanche species. $P$. aegyptiaca and P. ramose were observed parasitizing tomato plants in this field. Phelipanche shoots (28 samples) were randomly collected from a TYLCV-infected tomato field in Cyprus (70 to 80\%) and were screened for TYLCV infection in the lab. DNA was extracted from the shoots using a commercial kit (Qiagen Plant DNeasy Kit) and polymerase chain reaction (PCR) was performed according to the protocol described by Martinez-Culebras et al. [33]).

Parasite and virus inoculations. Tomato and tobacco seedlings (four to five leaves) were transplanted into 0.5-liter pots filled with soil (light to medium clay with $63 \%$ sand, $12 \%$ silt, and $22 \%$ clay) containing $P$. aegyptiaca seeds (20 mg seeds/liter soil, approximately 3,200 seeds/liter). A week after transplanting to soil containing $P$. aegyptiaca seeds, plants were mechanically infected with CMV, ToMV, and PVY. Tomato seedlings (three to four leaves) were infected by TYLCV 2 weeks prior to being transplanted into soil containing $P$. aegyptiaca seeds. The inoculated plants were grown for 2 months in a greenhouse under natural light, with an average $14 \mathrm{~h}$ of daylight and an average temperature of $20 \pm 6^{\circ} \mathrm{C}$. Mechanical inoculation with $\mathrm{CMV}$, ToMV, and PVY was performed by rubbing leaves after dusting with carborundum. Inocula were prepared by grinding young leaves from tobacco source plants in distilled water $(1: 5 \mathrm{wt} / \mathrm{wt}$, leaves/water). TYLCV inoculation was performed by adult whiteflies after acquisition on TYLCV-infected tomato source plants for $48 \mathrm{~h}$, as described by Lapidot et al. (29). Plants were watered and fertilized as necessary.

Host plants. To determine whether viable virus existed in Phelipanche tissues, back-inoculation was performed with Phelipanche extracts on susceptible test plants. Pools of three Phelipanche shoots (5 to $15 \mathrm{~cm}$ ) grown on two to three host plants were ground (ca. 1:5 tissue/water), and the extracts were used for mechanical inoculation of systemic and local lesion host plants (with three to four leaves). CMV infectivity was evaluated in Nicotiana glutinosa, N. tabacum L. cv. Samsun NN, and Chenopodium quinoa. ToMV infectivity was evaluated in N. tabacum L. cv. Samsun, N. benthamiana, N. glutinosa, C. quinoa, and $C$. amaranticolor. PVY infectivity was evaluated in $N$. glutinosa and N. tabacum L. cv. Samsun NN. The appearance of symptoms on the treated plants was evaluated during the 2 weeks following the inoculations.

RNA isolation and reverse transcription (RT)-PCR analysis. Total RNA was extracted from four leaf disks ( $9 \mathrm{~mm}$ diameter) collected from tobacco and tomato leaves (leaves three and four from the top), as well as from P. aegyptiaca tubercles, shoots, and flower organs (ca. $100 \mathrm{mg}$ fresh weight). P. aegyptiaca samples were pooled from three Phelipanche shoots grown on two to three different plants. RNA was isolated using the TRI-REAGENT kit (Molecular Research Center, Inc., Cincinnati, OH), according to the manufacturer's instructions. RNA concentrations were measured using a spectrophotometer (Nanodrop ND-1000, Nanodrop, Wilmington, DE) and comparable amounts of the different RNAs were subjected to RT-PCR analysis to detect the different viruses. RT-PCR analysis was used to examine the accumulation of CMV, ToMV, and PVY in host plants and $P$. aegyptiaca. The first-strand cDNA was synthesized using $1 \mu \mathrm{g}$ of total RNA extract and complementary primers specific to each virus using Verso cDNA Kit (ABgene, Epsom, UK) according to the manufacturer's instructions. Two microliters of the resulting cDNA was used as a template for a standard PCR. cDNA was denatured at $94^{\circ} \mathrm{C}$ for $4 \mathrm{~min}$, followed by 30 cycles of $94^{\circ} \mathrm{C}$ for $30 \mathrm{~s}, 58^{\circ} \mathrm{C}$ for $30 \mathrm{~s}$, and $72^{\circ} \mathrm{C}$ for $35 \mathrm{~s}$, and a final $5 \mathrm{~min}$ at $72^{\circ} \mathrm{C}$. For the PCR amplification of the CMV cDNA, we raised the annealing temperature to $62^{\circ} \mathrm{C}$. The primers used to detect CMV, ToMV, and PVY were as follows. Forward primer 5'-YASYTTTDRGGTTCAATTCC-3' and reverse primer 5'-GACTGACCATTTTAGCCG-3' were used for CMV RNA3 (935 nucleotide product). Forward primer 5'-ATGTCTTACAGTATCACTACTCCA-3' and reverse primer 5'-GTTGCAGGACCAGAGGTCCAAACC-3' were used for ToMV coat protein gene (475 nucleotide product). And, forward primer 5'-GTGTATCCCTGTTGTTGAC$3^{\prime}$ and reverse primer $5^{\prime}$-CCACCAACTCTATAGTGCTTAATG-3' were used for PVY HC-Pro (511 nucleotide product).

DNA extraction, PCR, and rolling circle amplification analysis. PCR and rolling circle amplification (RCA) were used to detect TYLCV in Phelipanche. Total DNA was extracted from TYLCV-infected tomato (four leaf disks, each $9 \mathrm{~mm}$ in diameter, ca. $150 \mathrm{mg}$ ) and from Phelipanche shoots (ca. $200 \mathrm{mg}$ ) according to the protocol described by Delaporta et al. (13). The extracted DNA $(1 \mu \mathrm{l})$ was diluted in $25 \mu \mathrm{l}$ of a PCR mixture containing the primer pair TYC1F (5'-GGGCCTAGAGACCTGGCCCAC-3') 
and TYC1R (5'-CCGGTAATATTATACGGATGGC-3'), as used by Lapidot et al. (29).

The PCR conditions were as follows: one cycle of $4 \mathrm{~min}$ at $94^{\circ} \mathrm{C}$, followed by 30 cycles at 94,58 , and $72^{\circ} \mathrm{C}$, each of $30 \mathrm{~s}$, and $5 \mathrm{~min}$ at $72^{\circ} \mathrm{C}$. We used one unit of Phusion High-Fidelity DNA polymerase (Finnzymes, Espoo, Finland) per reaction for the amplification of TYLCV.

The circular genomic DNA of TYLCV was amplified by RCA (17) using the TempliPhi amplification kit (GE Healthcare, Chalfont St. Giles, UK) as follows. One microliter of TYLCV-infected plant total DNA preparation was added to $5 \mu \mathrm{l}$ of the sample buffer, the mixture was heated to $95^{\circ} \mathrm{C}$ for $3 \mathrm{~min}$ to denature the DNA, and then snap-chilled on ice and combined with $5 \mu \mathrm{l}$ of reaction buffer plus $0.2 \mu \mathrm{l}$ of enzyme mix (containing Phi29 DNA polymerase and random hexamers in $50 \%$ glycerol). The reaction mixture was then incubated for $18 \mathrm{~h}$ at $30^{\circ} \mathrm{C}$, followed by inactivation of the enzyme at $65^{\circ} \mathrm{C}$ for $10 \mathrm{~min}$. To detect TYLCV, the products of the RCA reaction $(1 \mu \mathrm{l})$ were digested using the $A p a \mathrm{I}$ restriction enzyme. The following bands were expected from the TYLCV digestion using the ApaI restriction enzyme: 1,300, 900 , and $600 \mathrm{bp}$. The TYLCV digestion pattern was confirmed by agarose gel analysis.

CMV purification. CMV was purified from tobacco $(N$. tabacum cv. Xanthi NN) leaves 2 months after inoculation (100 g) and from pools of Phelipanche shoots (ca. $88 \mathrm{~g}$ ) grown on three infected tobacco plants, as previously described by Palukaitis et al. (40). CMV particles were observed using EM Tecnai $\mathrm{G}^{2}$ Spirit TEM (FEI Company, Philips, Netherlands).

Detection of viral coat protein by western blot analysis. At 65 days postinfection, protein samples were collected from the virus-infected host plants (tobacco or tomato) and from Phelipanche grown on those plants. Total protein was extracted by grinding pooled samples of six leaf disks ( $9 \mathrm{~mm}$ diameter; ca. 70 mg total fresh weight) taken from the young tobacco and tomato leaves, as well as pooled samples from Phelipanche shoots (70 $\mathrm{mg}$ fresh weight). The protein samples were extracted in 150 $\mu \mathrm{l}$ of ESB buffer $(75 \mathrm{mM}$ Tris/ $\mathrm{HCl}, \mathrm{pH} 6.8 ; 9 \mathrm{M}$ urea; $4.5 \%$ [vol/vol] sodium dodecyl sulfate [SDS]; and 7.5\% [vol/vol] $\beta$ mercaptoethanol). The samples were boiled for $5 \mathrm{~min}$ and were centrifuged for $10 \mathrm{~min}$ at $10,000 \times g$. Then, a 1:1 mixture of the supernatant was mixed with $2 \times$ SDS-polyacrylamide gel electrophoresis (PAGE) loading buffer and $10 \mu$ l of supernatant from each sample was fractionated by SDS-PAGE on a $15 \%$ polyacrylamide gel. The fractionated proteins were electroblotted onto nitrocellulose membranes (Amersham Biosciences, Sweden), blocked with $1 \%$ nonfat dry milk for $1 \mathrm{~h}$ and probed with rabbit antiserum specific to either LS-CMV CP (1:2,000 dilution) or ToMV CP (1:5,000 dilution) overnight at $4^{\circ} \mathrm{C}$. The membranes were washed three times with Tris-buffered saline-Tween and then incubated with goat anti-rabbit IgG conjugated to alkaline phosphatase (1:4,000 dilution). The viral capsid proteins were visualized by incubating the membranes with the chromophore substrates NBT and BCIP (Promega, WI) according to the manufacturer's instructions.

Detecting the accumulation of CMV siRNA in the host and parasite. To test for the presence of CMV siRNA in Phelipanche, total RNA was extracted from Phelipanche shoots that were grown on three plants and then ground to a fine powder with liquid nitrogen. RNA samples $(10 \mu \mathrm{g})$ were separated on $15 \%$ PAGE containing $7 \mathrm{M}$ urea in a $0.5 \times$ Tris-borate EDTA as described by Shiboleth et al. (45). The separated RNAs were transferred to a Hybond NX membrane (Amersham Biosciences) and cross-linked to the membrane with highly sensitive EDC (1ethyl-3-(3-imethylaminopropyl) carbodiimide), as described by Pall et al. (38). The blot was hybridized with a ${ }^{32} \mathrm{P}$-labeled transcript. Sense transcripts were produced using an AmpliScib T7Flash $^{\mathrm{TH}}$ Transcription Kit (EPICENTER, WI) on a linear template of a pGEM-T plasmid harboring part of RNA3 of the CMV fragment $(935 \mathrm{bp})$. Prehybridization and hybridizations were performed as described previously (45). The membranes were exposed to a phosphorimager screen (Fuji) for about $3 \mathrm{~h}$.

\section{RESULTS AND DISCUSSION}

Phelipanche spp. (broomrape) is a parasitic plant that subsists on the roots of host plants, to which it connects via direct bridges of xylem and phloem tissue (15). These bridges allow the parasite to acquire water, minerals, carbohydrates, proteins, and probably nucleic acids $(4,19,22,44)$ as well. To date, viral infection has not been reported in this parasitic organism, even though plant RNA viruses such as CMV have been shown to multiply in parasitic Cuscuta (dodder) (7,9). Accordingly, our study concentrated on the acquisition of CMV by P. aegyptiaca from infected hosts.

Tobacco and tomato plants infected with Fny-CMV (subgroup I) showed typical leaf mosaic symptoms when grown in soil containing P. aegyptiaca seeds (Fig. 1A and B). Tobacco leaves infected with CMV showed a variety of symptoms. Some infected leaves showed typical mosaic symptoms, while others did not display any visible symptoms. Tomato plants infected with CMV showed severe symptoms (leaf deformation with mosaic symptoms and chlorosis were observed; Fig. 1A). No differences were observed in the symptoms of CMV-infected tomato and tobacco plants grown with or without the parasite $P$. aegyptiaca (data not shown). In addition, the height of CMV-infected tobacco plants was not affected by the presence of the parasitic plant (Table 1). However, the number of Phelipanche shoots per plant was significantly higher in uninfected tobacco than in CMV-infected plants 45 days postinoculation (dpi). However, at 65 dpi more parasitic shoots were observed in CMV-infected tobacco and the total number of Phelipanche shoots per plant was similar to that of the control, uninfected tobacco plants (Table 1), indicating a delay in the appearance of $P$. aegyptiaca on CMV-infected tobacco plants.

CMV infection has been shown to reduce the accumulation of carotenoids (41). Thus, it is possible that the delay in the appearance of shoots of Phelipanche grown on CMV-infected tobacco is due to an effect of CMV on secondary metabolite stimulators such as strigolacetones, which are produced via the carotenoid biosynthesis pathway (31). In addition, some inflorescences of Phelipanche grown on CMV-infected tobacco developed abnormally (deformed shoots and short nodes). In comparison, these abnormalities were not observed in the Phelipanche inflorescences on healthy host plants (Fig. 1D). As mentioned, these abnormalities appeared only in some of the inflorescences. Similarly, CMV-infected dodder grown on tobacco showed a range of growth abnormalities (9).

To confirm the presence of infectious CMV in $P$. aegyptiaca tissues, we back-inoculated both systemic (N. tabacum and $N$. glutinosa) and local lesion (C. quinoa) host plants with extract from $P$. aegyptiaca. Back-inoculation of $N$. tabacum with sap extract from parasitic shoots grown on tobacco and tomato plants resulted in systemic infectivity rates of 100 and $60 \%$, respectively (Table 2, CMV). These infectivity rates were similar to those observed for CMV-infected tobacco and tomato leaves (Table 2, CMV). Back-inoculation of $C$. quinoa led to the formation of typical local lesions, similar to those obtained when the plants were inoculated with extract from CMV-infected tobacco. These data indicate that the $P$. aegyptiaca grown on tobacco and tomato infected with CMV acquired the virus from its host and that viral infectivity was maintained. Similarly, in an earlier study, the accumulation of viable CMV in dodder stems was observed through the back-inoculation of $N$. tabacum and $N$. glutinosa $(7,9)$.

Additionally, we were able to detect CMV RNA in Phelipanche shoots grown on tobacco and tomato plants infected with CMV, using RT-PCR with specific primers corresponding to CMV 
RNA3 (Fig. 2). To test the distribution of CMV in the parasite's organs, total RNA from the tubercles, shoots, and flowers (stamen and stigma) of $P$. aegyptiaca grown on infected tobacco was extracted and subjected to RT-PCR (Fig. 2A). CMV RNA was detected in all of the examined $P$. aegyptiaca organs (Fig. 2A), indicating long-distance movement of the virus acquired from the host.

To examine CMV replication in Phelipanche cells, we tested the accumulation of CMV minus strand (Fig. 2C) using the same primers used for the analysis of CMV RNA3, in which the forward primer was used for first-strand synthesis. We were able to detect the minus strand of CMV RNA3 in all of the samples of Phelipanche shoots grown on CMV-infected tobacco (Fig. 2C) and tomato (data not shown). This result may indicate that CMV replicates in the parasite's cells. Interestingly, an indication of the multiplication of CMV in dodder was reported in earlier studies involving transfer inoculation and mechanical inoculation $(7,9)$.

The existence of viral small RNA (vsiRNA) in plant cells is additional, indirect evidence for virus replication, since vsiRNA is processed from dsRNA by the DCLs, which are part of the host's gene-silencing machinery (14). The accumulation of CMV siRNA has been demonstrated in several hosts of CMV (14). In our study, CMV-specific siRNA was detected in CMV-infected host plants and in shoots of P. aegyptiaca grown on tomato (Fig. 2D) and tobacco (data not shown). The detection of the minus strand of CMV siRNA using plus strand-labeled RNA transcript as a probe (Fig. 2D) provides additional evidence for the accumulation of minus-strand CMV RNA in the parasite's tissue. Our observation

TABLE 1. Effect of Cucumber mosaic virus (CMV)-infected tobacco on the appearance of Phelipanche aegyptiaca shoots

\begin{tabular}{lccc}
\hline & $\begin{array}{c}\text { Tobacco } \\
\text { height }(\mathrm{cm})\end{array}$ & \multicolumn{2}{c}{ Number of shoots } \\
\cline { 3 - 4 } & & $\mathrm{dpi}^{\mathrm{a}}$ & $65 \mathrm{dpi}$ \\
\hline Virus-free & 104 & 28 & 28 \\
$1^{\mathrm{b}}$ & 106 & 37 & 37 \\
2 & 75 & 26 & 26 \\
3 & 77 & 20 & 20 \\
4 & 85 & 36 & 36 \\
5 & & & \\
CMV-infected & 120 & 6 & 28 \\
1 & 130 & 6 & 47 \\
2 & 86 & 0 & 14 \\
3 & 110 & 10 & 25 \\
4 & 95 & 0 & 23 \\
5 & & &
\end{tabular}

a Days after inoculation with P. aegyptiaca.

b Plant replicates.

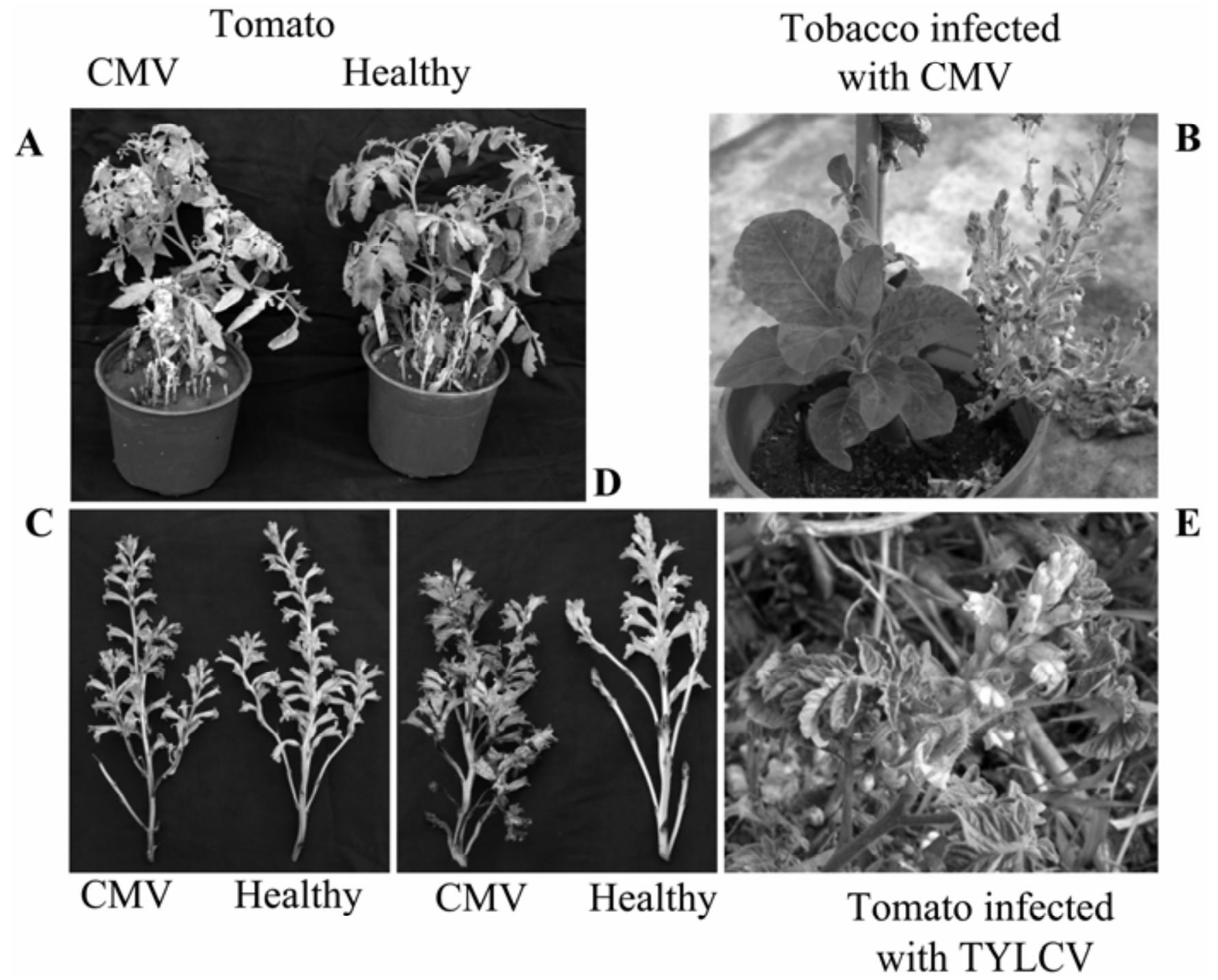

Fig. 1. Effect of Cucumber mosaic virus (CMV)-infected tobacco and tomato plants on Phelipanche aegyptiaca development. A, P. aegyptiaca growing on infected tomato (CMV) and uninfected (healthy) tomato. B, P. aegyptiaca growing on tobacco infected with CMV and mosaic symptoms on secondary tobacco shoots. C and D, Representative inflorescences of $P$. aegyptiaca grown on tobacco infected with CMV and control healthy tobacco. Pictures were taken 65 days after inoculation with Phelipanche seeds. E, Close-up picture of Phelipanche spp. growing on a Tomato yellow leaf curl virus-infected tomato plant in the field. 
of the accumulation of tasi mir390, which is processed by DCL4 in the cytosol from a nontranslated mRNA (27), in the parasite shoot (3) provides additional support for the existence of silencing machinery in Phelipanche.
Western blot analysis of total protein extracted from $P$. aegyptiaca shoots grown on tobacco plants infected with CMV detected the accumulation of CMV CP in Phelipanche (Fig. 3). We observed differences in the accumulation of CMV CP in two

TABLE 2. Infectivity rates of viruses from the shoots of Phelipanche aegyptiaca grown on plants infected with Cucumber mosaic virus (CMV), Tomato mosaic virus (ToMV), and Potato virus $Y$ (PVY)

\begin{tabular}{|c|c|c|c|c|c|c|}
\hline \multirow[b]{2}{*}{ Virus } & \multirow[b]{2}{*}{ Source of inocula } & \multicolumn{5}{|c|}{ Back-inoculation on a susceptible host ${ }^{\mathrm{a}}$} \\
\hline & & Nicotiana tabacum & N. benthamiana & N. glutinosa & Chenopodium quinoa & C. amaranticolor \\
\hline \multirow{4}{*}{$\overline{\mathrm{CMV}}$} & Tomato & $6 / 9$ & & $3 / 5$ & + & \\
\hline & Phelipanche & $18 / 29$ & & $2 / 5$ & + & \\
\hline & Tobacco & $5 / 5$ & & n.t. & + & \\
\hline & Phelipanche & $5 / 5$ & & n.t. & + & \\
\hline \multirow[t]{4}{*}{ ToMV } & Tomato & $8 / 8$ & $4 / 4$ & $4 / 4$ & n.t. & n.t. \\
\hline & Phelipanche & $11 / 11$ & $7 / 7$ & $4 / 4$ & n.t. & n.t. \\
\hline & Tobacco & $12 / 12$ & $4 / 4$ & n.t. & + & + \\
\hline & Phelipanche & $14 / 17$ & $2 / 4$ & n.t. & + & + \\
\hline \multirow[t]{2}{*}{ PVY } & Tobacco & $4 / 4$ & & $4 / 4$ & & \\
\hline & Phelipanche & $1 / 12$ & & $1 / 10$ & & \\
\hline
\end{tabular}

${ }^{a}$ n.t. $=$ not tested. $+=$ local lesions were observed but not counted.

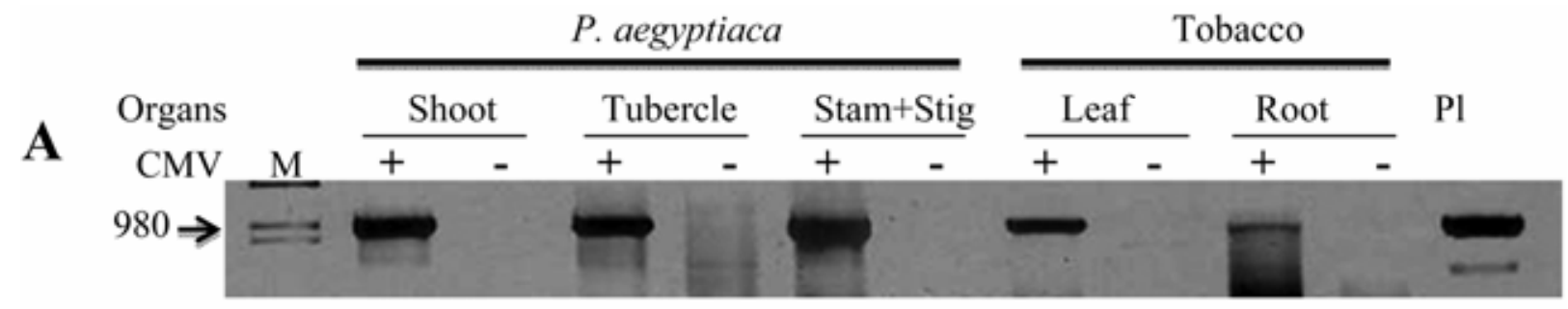

B

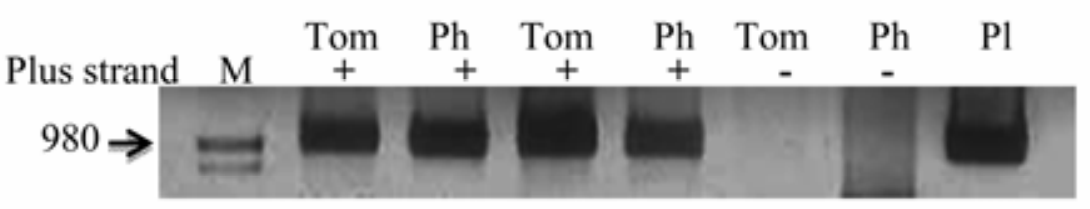

$\begin{array}{lccccccc}\text { C } & \text { Ph } & \text { Ph } & \text { Tom } & \text { Ph } & \text { Tom } & \text { Pl } & \text { Neg } \\ \text { Minus strand } & + & + & + & - & - & & \end{array}$

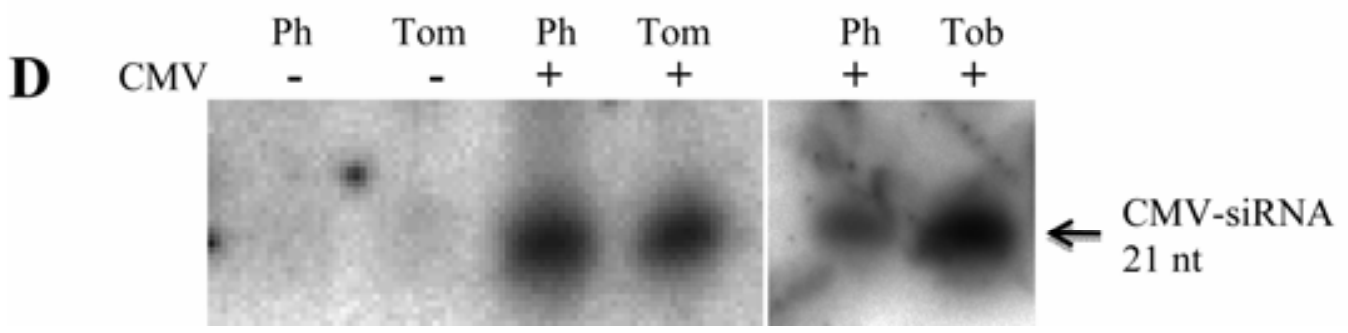

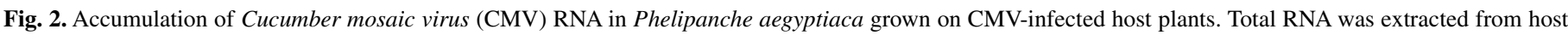

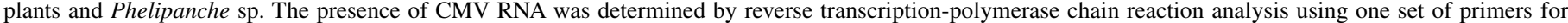

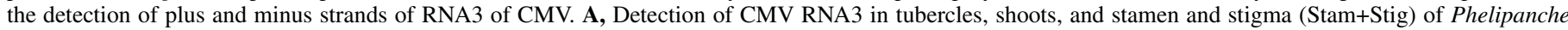

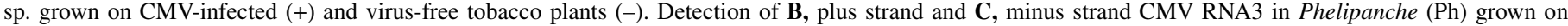

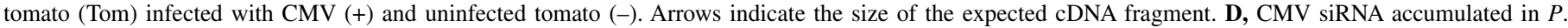

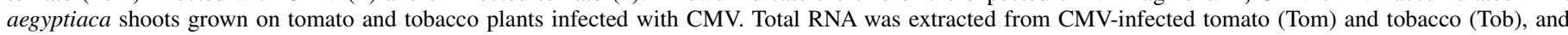

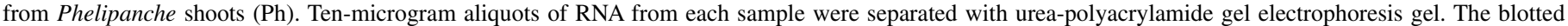

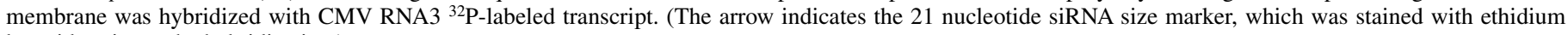
bromide prior to the hybridization.) 
tobacco plants (Tob1 and Tob2 Fig. 3A). This could be explained by the slight difference in the quantities loaded in the gel and/or by differences in the accumulation of the virus in different tobacco leaves. However, the difference in the accumulation of $\mathrm{CP}$ in the different samples of tobacco leaves was less pronounced than the difference in the accumulation of $\mathrm{CP}$ in different Phelipanche shoots (Ph 1 and Ph 2, Fig. 3A).

The detection of CMV RNAs and CP in P. aegyptiaca led us to verify the accumulation of CMV particles in Phelipanche organs. CMV particles were isolated from tobacco leaves and from aerial Phelipanche organs (shoots and flowers) 55 days after the plants were inoculated with $\mathrm{CMV}$, using common purification methods. Purified CMV virions were successfully extracted from Phelipanche organs, and the concentration of $16 \mathrm{mg} / \mathrm{ml}$ was equivalent to $170 \mathrm{mg} / \mathrm{kg}$ from parasitic tissues compared with $20 \mathrm{mg} / \mathrm{ml}$ $(220 \mathrm{mg} / \mathrm{kg}$ ) from tobacco leaves. The comparable levels of virus accumulation in the host and the parasite may indicate similar replication rates in the different plants or similar stability in the cells of tobacco and Phelipanche. Transmission electron microscopy confirmed the presence of typical isometric CMV particles in the examined aerial organs of Phelipanche (Fig. 4), which were comparable to particles isolated from tobacco leaves.

These results demonstrate, for the first time, that the parasite $P$. aegyptiaca is a host for CMV. Therefore, we decided to examine the susceptibility of Phelipanche to additional viruses belonging to different groups, such as ToMV (type member of the tobamoviruses), PVY (type member of the potyviruses), and TYLCV (a geminivirus). Phelipanche grown on ToMV-infected tomato and tobacco did not show any visible developmental abnormalities, as were observed in parasite tissue infected with CMV. In this case, the parasitic Phelipanche was not altered by its association with ToMV-infected tomato or tobacco plants (data not shown).

Back-inoculation of test plants with extracts from Phelipanche shoots grown on ToMV-infected tomato and tobacco demonstrated systemic infectivity in N. tabacum and N. glutinosa and induced the formation of local lesions in $C$. quinoa and $C$. amaranticolor (Table 2, ToMV). RT-PCR analysis detected the presence of plus and minus strands of ToMV RNA in Phelipanche grown on tomato infected with ToMV (Fig. 5). ToMV coat protein could barely be detected in Phelipanche shoots grown on ToMV-

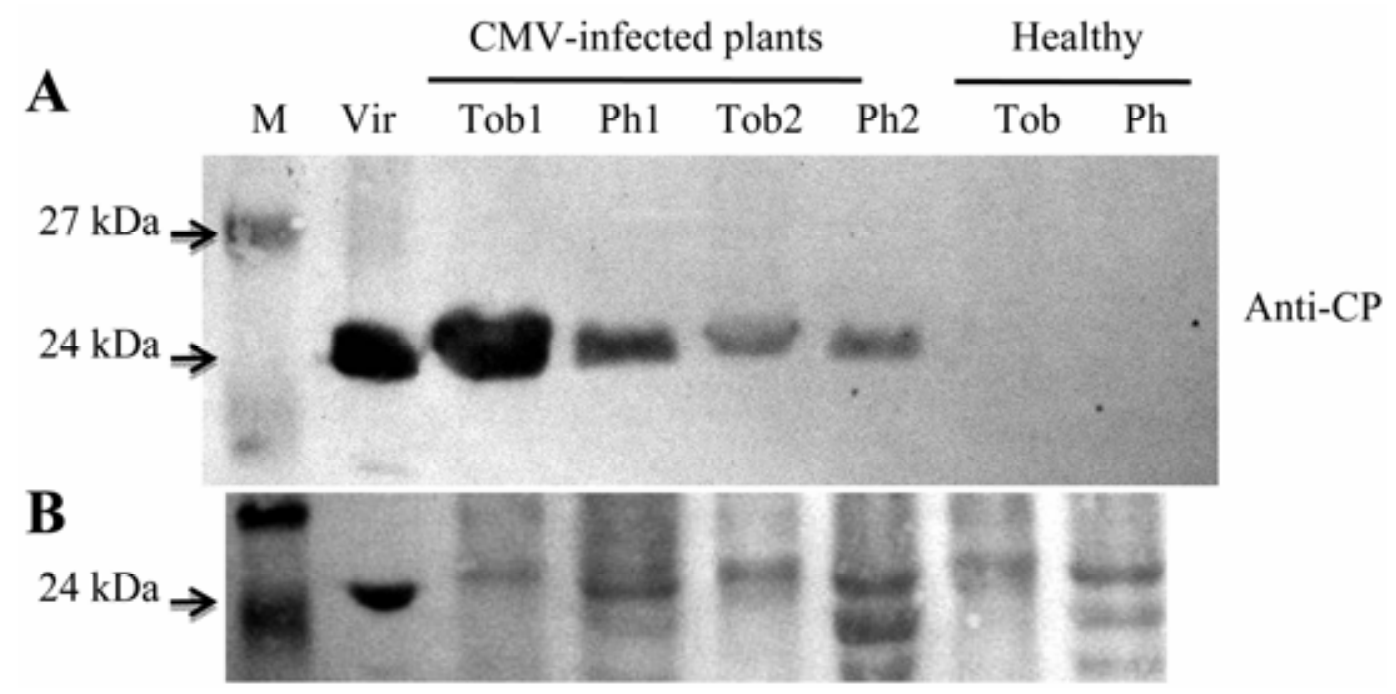

Fig. 3. Cucumber mosaic virus (CMV) coat protein (CP) accumulated in Phelipanche aegyptiaca grown on CMV-infected tobacco. A, Immunoblotting of CMV $\mathrm{CP}$ in tobacco leaves (Tob) and Phelipanche shoots ( $\mathrm{Ph}) 65$ days after inoculation with the parasite seeds. Total protein was extracted from CMV-infected and uninfected tobacco leaves (200 mg from two plants, Tob1 and Tob2) and from Phelipanche shoots (200 mg from Ph1 and Ph2) grown on those tobacco plants. Leaf extracts from virus-free tobacco (Healthy) and Phelipanche that grew on this plant served as controls. Fifteen microliters from each sample were separated on sodium dodecyl sulfate-polyacrylamide gel electrophoresis, and the blotted membrane was immunoblotted with CMV antibodies (anti-CP) at a 1:2,000 dilution. B, Ponceau staining demonstrated the amount of total protein loaded. Purified CMV virus (Vir) served as a positive control. Arrows indicate the sizes of the nearest protein marker (M) bands.
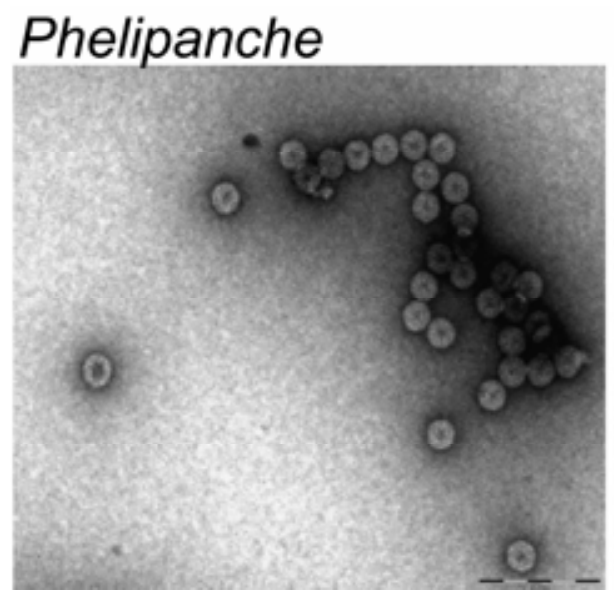

\section{tobacco}

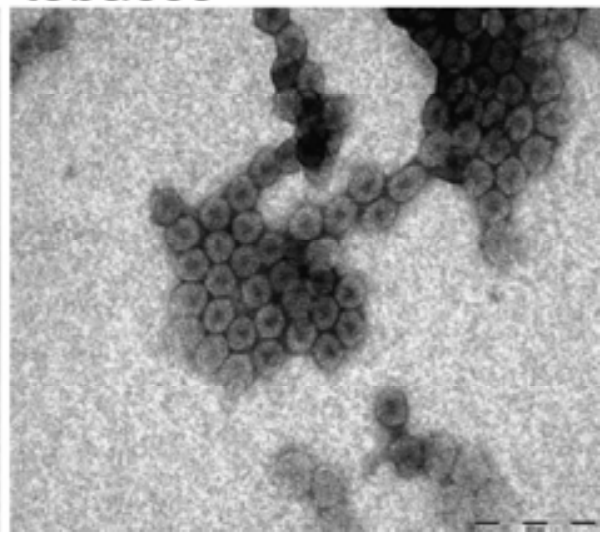

Fig. 4. Cucumber mosaic virus (CMV) particles accumulated in Phelipanche aegyptiaca shoots. Electron micrographs of CMV particles from purified preparations of CMV-infected tobacco and Phelipanche shoots that grew on those tobacco plants. Magnification factor: $\times 135,000$. Bars represent $100 \mathrm{~nm}$. 
infected tomato (Fig. 5C). Very low accumulation of coat protein was observed in Phelipanche shoots grown on one out of two tomato plants, as compared to the high level of coat protein accumulation observed in host tissue infected with ToMV (Fig. 5C). A small amount of ToMV coat protein was found in Phelipanche, and the fact that we could not observe virus particles in the dip preparation examined under the transmission electron microscope may indicate a very low rate of replication of ToMV in the parasite. Alternatively, ToMV may not replicate in the parasite's cells and the detection of ToMV plus and minus strands may have been the result of the movement of nonencapsidated RNA from the ToMV-infected host into Phelipanche.

TMV RNA can move as a ribonucleoprotein complex (20). Therefore, it is possible that the movement of ToMV from the host to the parasite Phelipanche is based on a mechanism similar to that reported for the movement of host-mobile mRNA transcripts into dodder $(11,44)$. Interestingly, Costa (9) demonstrated a similar result. That study showed that TMV does not persist in dodder, suggesting the passive movement of TMV with the reversals of phloem nutrient flow, allowing virus transmission between plants.

Tobacco plants infected with $\mathrm{PVY}^{\mathrm{H}}$ showed severe developmental defects, such as stunting and leaf necrosis around the veins. Phelipanche shoots grown on PVY-infected tobacco appeared late, as observed with CMV. Moreover, the number of shoots per host plant was about one-third that of Phelipanche grown on virus-free tobacco 60 dpi (data not shown). The pres- ence of PVY in Phelipanche shoots was determined by backinoculation and by RT-PCR, as with ToMV and CMV. Extracts from Phelipanche shoots grown on PVY-infected tomato were not infectious on tobacco test plants, and a low rate of infectivity $(2: 22)$ was observed for extracts from Phelipanche grown on PVY-infected tobacco (Table 2). However, back-inoculation with an extract from host plant leaves infected with PVY exhibited $100 \%$ infectivity on test plants. In addition, RT-PCR analysis detected PVY RNA in Phelipanche grown on tobacco plants infected with PVY, but not in Phelipanche grown on tomato plants infected with PVY (Fig. 6A). The weaker cDNA band of PVY obtained from the RT-PCR analysis of Phelipanche grown on tobacco plants (Fig. 6A) is representative of similar results obtained in three biological repeats. These results may indicate a low level of PVY in Phelipanche grown on PVY-infected host plants. The existence of PVY in parasitic plants has not been described previously, although the transmission of a potyvirus by dodder has been reported (23). The above-mentioned RNA viruses (CMV, ToMV, and PVY) replicate and accumulate in the cytosol of plant cells (i.e., mesophyll). Therefore, we decided to examine additional virus such as geminivirus, which are restricted to phloem cells.

Phelipanche physically attaches to hosts by haustorial structures, through which nutrients from the host xylem and phloem enter the parasite. Such a connection is predicted to allow the trafficking of small geminivirus particles especially TYLCV which are found in roots (34).
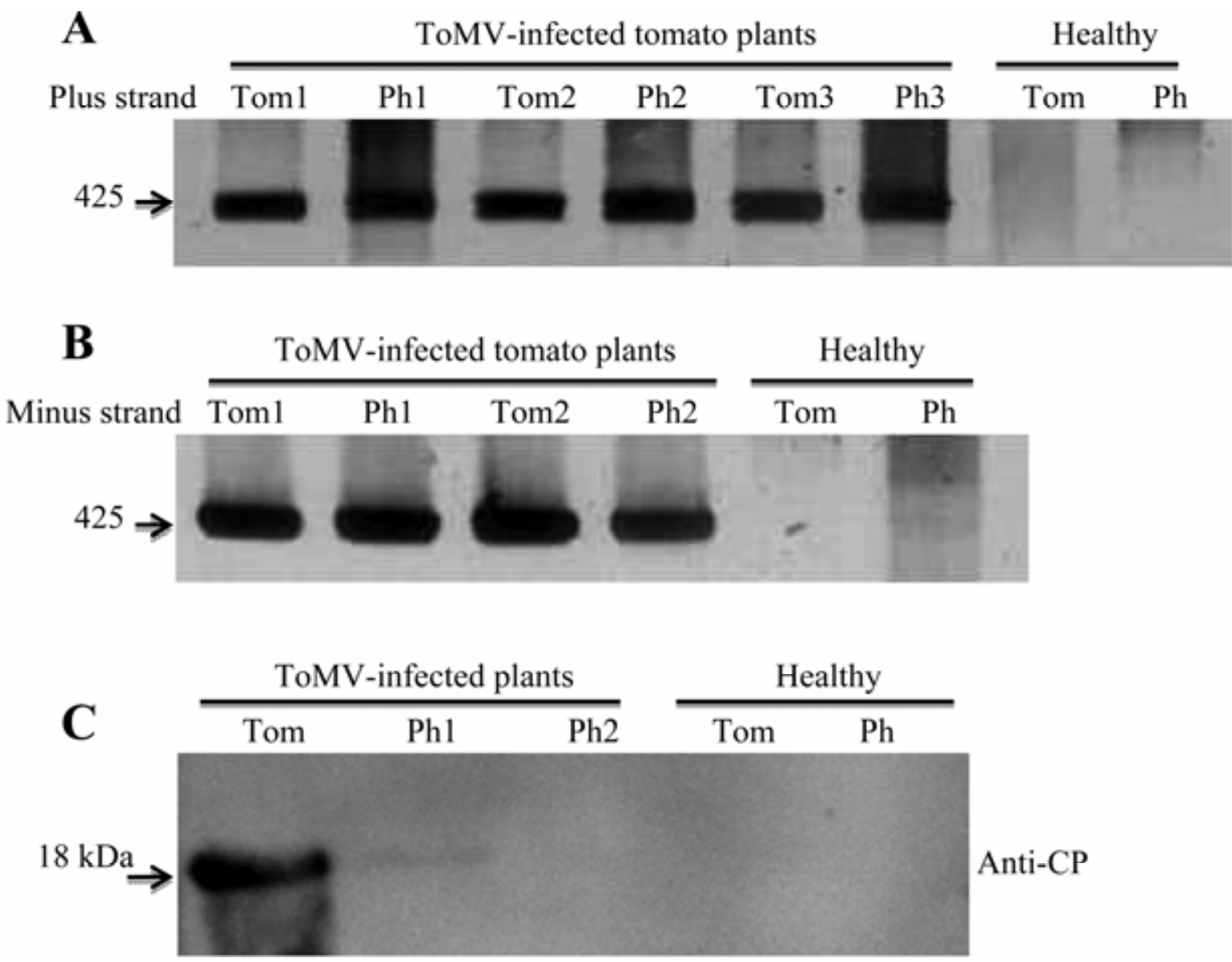

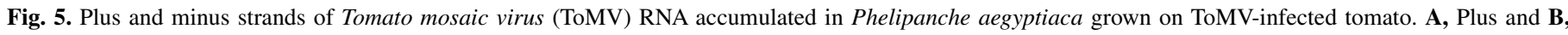

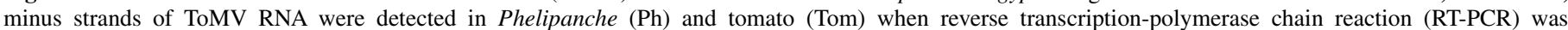

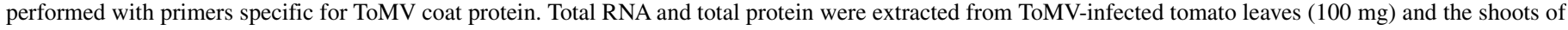

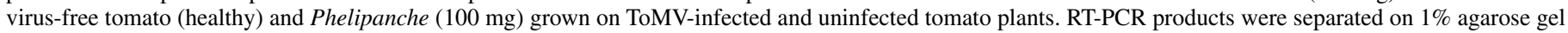

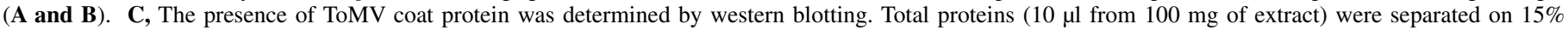

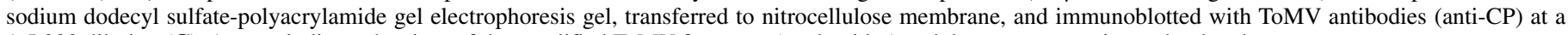
1:5,000 dilution $(\mathbf{C})$. Arrows indicate the sizes of the amplified ToMV fragment (nucleotides) and the nearest protein marker bands. 
TYLCV-infected tomato plants showed symptoms typical of viral infection, such as curled leaves and stunted growth. The shoots of Phelipanche grown on infected tomato appeared later than those of Phelipanche grown on virus-free tomato, and the number of shoots per plant was reduced. The presence of TYLCV in Phelipanche was determined by PCR and by RCA. Total DNA was extracted from Phelipanche shoots grown on four tomato plants. Using TYLCV specific primers, a predicted fragment was PCR-amplified from the four TYLCV-infected tomato plants, but not from the virus-free tomato plants (Fig. 6B). In four biological replicates, the intensities of the PCR-amplified fragment from Phelipanche shoots were lower than the intensities of those from infected tomato leaves after 30 cycles (Fig. 6B). We do not have an explanation for the lower bands that appeared in the third sample (Or3), although similar faint PCR bands can be seen in tomato leaves from plant No. 3 (Fig. 6B, tom3). Using RCA amplification technology, the intact circular ssDNA of TYLCV was identified in Phelipanche shoots. The amplified ssDNA obtained from Phelipanche shoots and tomato leaves was digested by ApaI. Fragments of a similar size were obtained from TYLCVinfected tomato leaves and Phelipanche shoots, and these fragments provide further evidence for the movement of circular TYLCV ssDNA molecules from host to parasite (Fig. 6C); however replication of TYLCV in the parasite needs to be confirmed.

These data were strengthened by our finding of Phelipanche plants that had been found to harbor TYLCV in the field. In collaborative work carried out during 2007 and 2008, a field survey was conducted to identify weed hosts of Tomato yellow leaf curl virus (TYLCV) in Cyprus. In the Kokkinotrimithia area, which is located in the Nicosia district, we observed that Phelipanche species ( $P$. ramose or $P$. aegyptiaca) were parasitizing tomato plants that were infected with TYLCV. Typical TYLCV symptoms (leaf curling, yellowing and stunting) were observed in a tomato field that had a 70 to $80 \%$ infection incidence (Fig. 1E). However, Phelipanche weeds growing on those TYLCV-infected tomato plants did not show significant symptoms (Fig. 1E). PCR analysis indicated that 12 of 28 Phelipanche samples collected in the field survey were infected with TYLCV. This is the first documented case of virus-infected Phelipanche in a field. Similarly, TYLCV was also detected in Cuscuta in a field survey in Spain (28).

Plasmodesmata have been shown to exist in Phelipanche (24). Therefore, we assume that cell-to-cell movement of plant viruses in Phelipanche is probably similar to the movement of viruses in photosynthetic plants. Viruses' penetration of host cells via haustorial connections has not been reported. This penetration probably involves symplasmic connections, such as the interspecific plasmodesmata observed between host and parasite phloem (15). Additionally, we observed that, unlike dodder, Phelipanche is not a host to all viruses. This is normal and characteristic of photosynthetic host plants. The accumulation of viruses in the seeds of a parasitic plant and transmission of viruses via these seeds has been observed in Cuscuta campestris (6) and should be studied further in Phelipanche species.
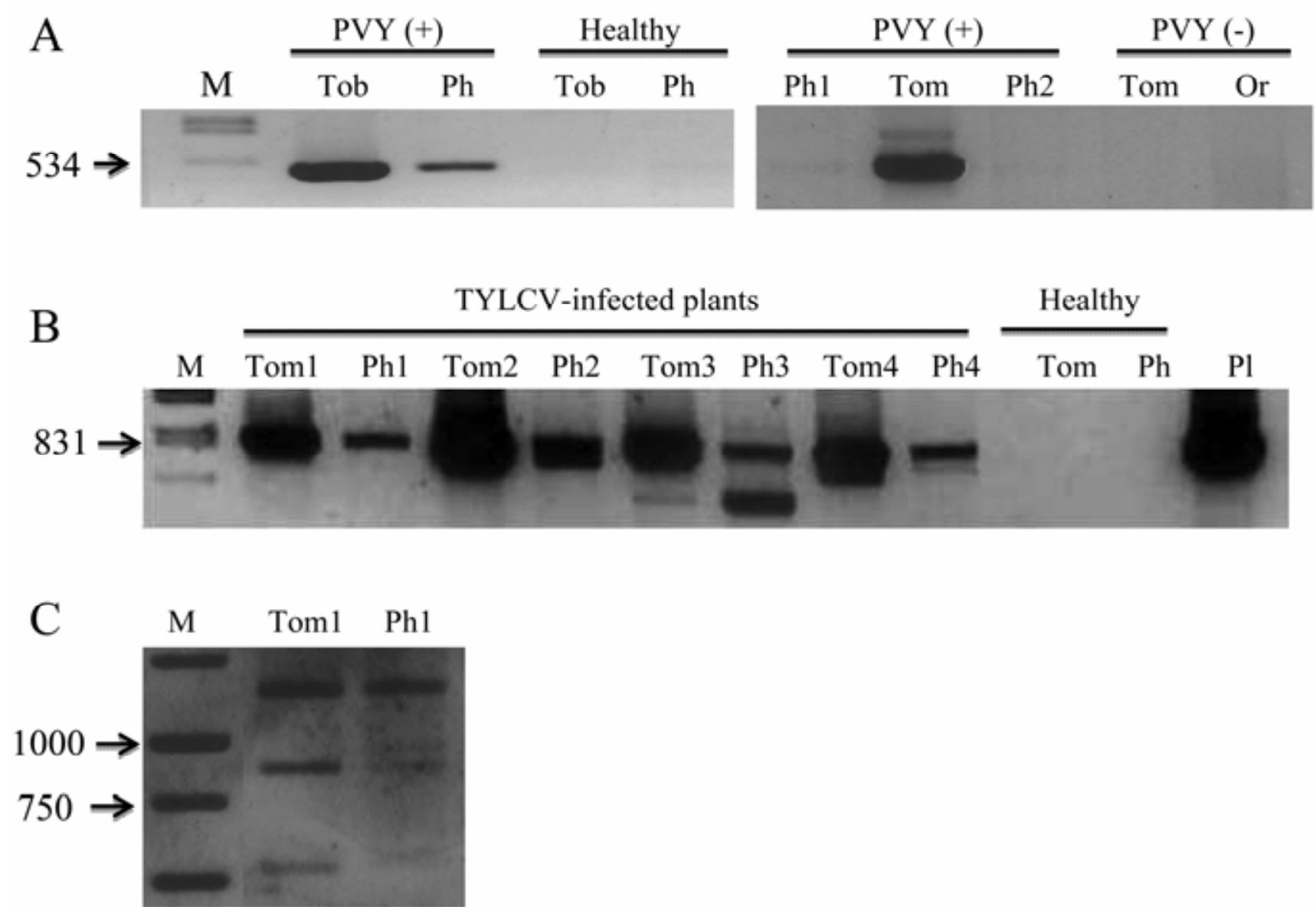

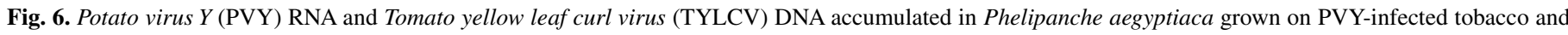

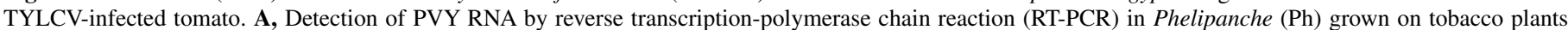

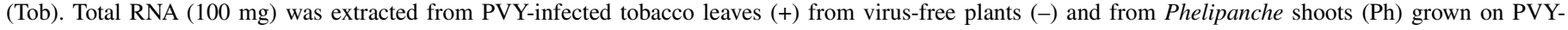

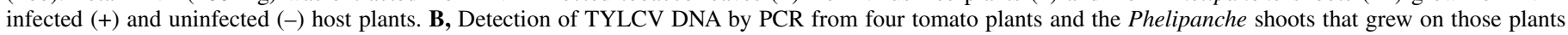

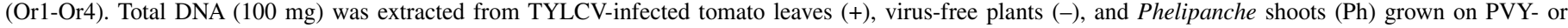

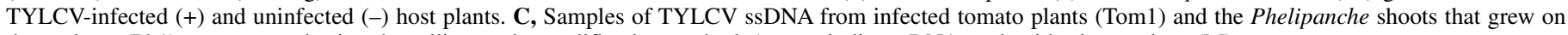
these plants (Ph1) were assayed using the rolling cycle amplification method. Arrows indicate DNA nucleotide size markers (M). 


\section{ACKNOWLEDGMENTS}

Contribution from the Agricultural Research Organization, The Volcani Center, Bet Dagan, Israel, No 511/09. This work was supported by the Chief Scientist of the Israel Ministry of Agriculture and Rural Development grant no. 1265-132.

\section{LITERATURE CITED}

1. Aber, M., Fer, A., and Sallé, G. 1983. Etude du transfert des substances organiques de l'hôte (Vicia faba) vers le parasite (Orobanche crenata Forsk.). Z. Pflanzenphysiol. 112:297-308.

2. Aly, R. 2007. Conventional and biotechnological approaches for control of parasitic weeds. In Vitro Cell Dev. Biol. Plant 43:304-317.

3. Aly, R., Cholakh, H., Joel, D. M., Leibman, D., Steinitz, B., Zelcer, A., Naglis, A., Yarden, O., and Gal-On, A. 2009. Gene silencing of mannose 6-phosphate reductase in the parasitic weed Orobanche aegyptiaca through the production of homologous dsRNA sequences in the host plant. Plant Biotechnol. J. 7:487-498.

4. Aly, R., Plakhin, D., and Achdari, G. 2006. Expression of sarcotoxin IA gene via a root-specific top promoter enhanced host resistance against parasitic weeds in tomato plants. Plant Cell Rep. 25:297-303.

5. Bennett, C. W. 1940. Acquisition and transmission of viruses by dodder (Cuscuta subinclusa). (Abstr.) Phytopathology 30:2.

6. Bennett, C. W. 1944. Latent virus of dodder and its effects on sugar beet and other plants. Phytopathology 34:77-91.

7. Bennett, C. W. 1944. Studies of dodder transmission of plant viruses. Phytopathology 34:905-932.

8. Boevink, P., and Oparka, K. J. 2005. Virus-host interactions during movement processes. Plant Physiol. 138:1815-1821.

9. Costa, A. S. 1944. Multiplication of virus in dodder, Cuscuta campestris. Phytopathology 34:151-162.

10. Czosnek, H. 2007. Tomato Yellow Leaf Curl Virus Disease. Springer, Netherlands.

11. David-Schwartz, R., Runo, S., Townsley, B., Machuka, J., and Sinha, N. 2008. Long-distance transport of mRNA via parenchyma cells and phloem across the host-parasite junction in Cuscuta. New Phytol. 179:1133-1141.

12. Davis, C. C., and Wurdack, K. J. 2004. Host-to-parasite gene transfer in flowering plants: Phylogenetic evidence from Malpighiales. Science 305:676-678.

13. Delaporta, S. L., Wood, J., and Hicks, J. B. 1983. A plant DNA minipreparation. Version II. Plant Mol. Biol. Rep. 4:19-21.

14. Diaz-Pendon, J. A., Li, F., Li, W. X., and Ding, S. W. 2007. Suppression of antiviral silencing by cucumber mosaic virus $2 b$ protein in Arabidopsis is associated with drastically reduced accumulation of three classes of viral small interfering RNAs. Plant Cell 19:2053-2063.

15. Dörr, I., and Kollemann, R. 1995. Symplasmic sieve element continuity between Orobanche and its host. Bot. Acta 108:47-55.

16. Eizenberg, H., Hershenhorn, J., Graph, S., and Manor, H. 2003. Orobanche aegyptiaca control in tomato with sulfonylurea herbicides. Acta Hort. 613:205-208.

17. Haible, D., Kober, S., and Jeske, H. 2006. Rolling circle amplification revolutionizes diagnosis and genomics of geminiviruses. J. Virol. Methods 135:9-16.

18. Hamamouch, N., Westwood, J. H., Banner, I., Cramer, C. L., Gepstein, S., and Aly, R. 2005. A peptide from insects protects transgenic tobacco from a parasitic weed. Transgenic Res. 14:227-236.

19. Haupt, S., Oparka, K., Sauer, N., and Neumann, S. 2001. Macromolecular trafficking between Nicotiana tabacum and the holoparasite Cuscuta reflexa. J. Exp. Bot. 52:173-177.

20. Heinlein, M. 2002. The spread of Tobacco mosaic virus infection: Insights into the cellular mechanism of RNA transport. Cell. Mol. Life Sci. 59:58-82.

21. Heinlein, M., and Epel, B. L. 2004. Macromolecular transport and signaling through plasmodesmata. Int. Rev. Cytol. 235:93-164.

22. Hibberd, J. M., and Jeschke, W. D. 2001. Solute flux into parasitic plants. J. Exp. Bot. 52:2043-2049.

23. Hosford, R. M. J. 1967. Transmission of plant viruses by dodder. Bot. Rev. 33:387-406.

24. Joel, D. M., Hershenhorn, Y., Eizenberg, H., Aly, R., Ejeta, G., Rich, P. J., Ransom, J. K., Sauerborn, J., and Rubiales, D. 2006. Biology and management of weedy root parasites. Pages 267-350 in: Horticultural Reviews. J. Janick, ed. John Wiley \& Sons, Hoboken, NJ.
25. Joel, D. M., Kleifeld, Y., Losner-Goshen, D., Herzlinger, G., and Gressel, J. 1995. Transgenic crops against parasites. Nature 374:49-50.

26. Joel, D. M., Losner-Goshen, D., Goldman-Guez, T., and Portnoy, V. H. 1998. The Haustorium of Orobanche. Paper read at current problems in Orobanche research. Proc. 4th Int. Workshop on Orobanche at Albena, Bulgaria.

27. Jones-Rhoades, M. W., Bartel, D. P., and Bartel, B. 2006. MicroRNAS and their regulatory roles in plants. Annu. Rev. Plant Biol. 57:19-53.

28. Jordá, C., Font, I., Martínez, P., Juarez, M., Ortega, A., and Lacasa, A. 2001. Current status and new natural hosts of Tomato yellow leaf curl virus in Spain. Plant Dis. 85:445.

29. Lapidot, M., Friedmann, M., Pilowsky, M., Ben-Joseph, R., and Cohen, S. 2001. Effect of host plant resistance to Tomato yellow leaf curl virus on virus acquisition and transmission by its whitefly vector. Phytopathology 91:1209-1213.

30. Liu, J. Z., Blancaflor, E. B., and Nelson, R. S. 2005. The tobacco mosaic virus 126-kilodalton protein, a constituent of the virus replication complex, alone or within the complex aligns with and traffics along microfilaments. Plant Physiol. 138:1853-1865.

31. Lopez-Raez, J. A., Charnikhova, T., Gomez-Roldan, V., Matusova, R., Kohlen, W., De Vos, R., Verstappen, F., Puech-Pages, V., Becard, G., Mulder, P., and Bouwmeester, H. 2008. Tomato strigolactones are derived from carotenoids and their biosynthesis is promoted by phosphate starvation. New Phytol. 178:863-874.

32. Lucas, W. J. 2006. Plant viral movement proteins: Agents for cell-to-cell trafficking of viral genomes. Virology 344:169-184.

33. Martínez-Culebras, P. V., Font, I., and Jordá, C. 2001. A rapid PCR method to discriminate between Tomato yellow leaf curl virus isolates. Ann. Appl. Biol. 139:251-257.

34. Michelson, I., Zamir, D., and Czosnek, H. 1994. Accumulation and translocation of Tomato yellow leaf curl virus (TYLCV) in a Lycopersicon esculentum breeding line containing the $L$. chilense TYLCV tolerance gene Ty-1. Phytopathology 84:928-933.

35. Mower, J. P., Stefanovic, S., Young, G. J., and Palmer, J. D. 2004. Plant genetics: Gene transfer from parasitic to host plants. Nature 432:165-166.

36. Nandula, V. K., Foy, C. L., and Orcutt, D. M. 1999. Glyphosate for Orobanche aegyptiaca control in Vicia sativa and Brassica napus. Weed Sci. 47:486-491.

37. Navot, N., Pichersky, E., Zeidan, M., Zamir, D., and Czosnek, H. 1991. Tomato yellow leaf curl virus: A whitefly-transmitted geminivirus with a single genomic component. Virology 185:151-161.

38. Pall, G. S., Codony-Servat, C., Byrne, J., Ritchie, L., and Hamilton, A. 2007. Carbodiimide-mediated cross-linking of RNA to nylon membranes improves the detection of siRNA, miRNA and piRNA by northern blot. Nucleic Acids Res. 35:e60.

39. Palukaitis, P., and Garcia-Arenal, F. 2003. Cucumoviruses. Adv. Virus Res. 62:241-323.

40. Palukaitis, P., Roossinck, M. J., Dietzgen, R. G., and Francki, R. I. 1992. Cucumber mosaic virus. Adv. Virus Res. 41:281-348.

41. Prakash, D., Raj, S. K., and Singh, B. P. 1995. Biochemical changes in Cucumber mosaic virus (CMV)-infected Amaranthus and Chenopodium. J. Sci. Food Agric. 68:299-303.

42. Riechmann, J. L., Lain, S., and Garcia, J. A. 1992. Highlights and prospects of potyvirus molecular biology. J. Gen. Virol. 73:1-16.

43. Rizzo, T. M., and Palukaitis, P. 1990. Construction of full-length cDNA clones of Cucumber mosaic virus RNAs 1, 2 and 3: Generation of infectious RNA transcripts. Mol. Gen. Genet. 222:249-256.

44. Roney, J. K., Khatibi, P. A., and Westwood, J. H. 2007. Cross-species translocation of mRNA from host plants into the parasitic plant dodder. Plant Physiol. 143:1037-1043.

45. Shiboleth, Y. M., Haronsky, E., Leibman, D., Arazi, T., Wassenegger, M., Whitham, S. A., Gaba, V., and Gal-On, A. 2007. The conserved FRNK box in HC-Pro, a plant viral suppressor of gene silencing, is required for small RNA binding and mediates symptom development. J. Virol. 81:13135-13148.

46. Surov, T., Aviv, D., Aly, R., Joel, D. M., Goldman-Guez, T., and Gressel, J. 1998. Generation of transgenic asulam-resistant potatoes to facilitate eradication of parasitic broomrapes (Orobanche spp.), with the sul gene as the selectable marker. Theor. Appl. Gen. 96:132-137.

47. Thole, V., Dalmay, T., Burgyan, J., and Balazs, E. 1993. Cloning and sequencing of potato virus Y (Hungarian isolate) genomic RNA. Gene, 123:149-56.

48. Tomilov, A. A., Tomilova, N. B., Wroblewski, T., Michelmore, R., and Yoder, J. I. 2008. Trans-specific gene silencing between host and parasitic plants. Plant J. 56:389-397. 